\title{
The relationship between motivations of architectural designers and environmentally sustainable construction design
}

Abstract

Research on sustainability in construction design has tended to focus on technological, institutional and economic drivers but there has been little change in the industry. Social scientific approaches offer insights on the lack of progress. However, few previous studies have investigated psychological factors despite the pivotal role of the individual professional decision-maker. The aim was to understand what personal motivations drive architectural designers to pursue sustainable design in their work and whether non-environmental motivations can drive sustainable outcomes. Twentyeight architectural designers in fourteen small firms in the London area were interviewed. Thematic analysis was conducted, informed by the self-determination theory of motivation. Although extrinsic motivators were noted, autonomous motivations including a moral imperative and personal commitment predominated. Further, the participants demonstrated other self-determined motivations including realisation of self-identity, pursuit of quality in design and awareness of their work's impact on people. These autonomous motivations align closely with sustainability principles including design for durability, high standards and technical expertise. The findings point to the risks of reliance on extrinisic motivators such as regulation, and the opportunities to engage architectural designers more extensively in sustainable design by linking sustainability to autonomous motivations.

Keywords: Architect, motivation, self-determination theory, sustainable design. 


\section{INTRODUCTION}

The construction industry has a particular responsibility to improve its environmental

impact. Reports from the Intergovernmental Panel on Climate Change (IPCC) make clear the importance of the built environment to climate change, and the potential to contribute to mitigation. Buildings consume around one third of global energy, and generate about the same proportion of black carbon emissions (i.e. carbon in particulate form which has a much higher warming potential than $\mathrm{CO}_{2}$; Intergovernmental Panel on Climate Change 2014). Construction and demolition waste forms approximately $30 \%$ of all waste generated in the EU (European Union 2015) and the construction industry is responsible for extraction of almost half of all raw materials globally (United Nations Environmental Programme 2014). Energy use and emissions are predicted to increase two- to three-fold by mid-century due to trends including population growth, urban migration and provision of adequate housing in developing countries. However, the IPCC report also describes the enormous potential for the industry to have a positive impact on mitigation, proposing that rates of energy use could flatten or even decrease if existing best practices and technologies become 'business as usual' throughout the industry (IPCC 2014).

Research on sustainability in construction has burgeoned over the last two decades (Davies et al. 1997, Hill and Bowen 1997, Kibert 2007, Clarke et al. 2008, Davies and Oreszczyn 2012). Nevertheless, consensus appears to be that while attitudes and action have made some progress, too little has changed (Myers 2005, Sayce, Ellison and Parnell 2007, Smyth 2013). In his brief overview of advancement, Kibert (2007: 595) noted that much has been achieved in high performance green buildings but the same materials still tend to be used; design for deconstruction is still in its early days; and the domains of green materials and the application of nature within buildings require much greater development: "in short, progress has been made but the difficult problems remain unsolved". Kibert pointed to previous work on definitions and principles, sustainability in a variety of contexts, assessment mechanisms and process issues. Other approaches have included exploration of technological advancement and innovation, and of market conditions. 
The current study offers a novel and complementary approach, taking a psychological perspective on the motivations of architectural designers.

The focus was on professionals involved in design for construction, including engineers as well as architects, here collectively termed 'architectural designers'. It has been argued that the majority of the environmental impact of a building is determined in the early stages of its design (Halliday 2007), placing the designer in a central and highly influential role for sustainable outcomes. The pivotal role of design in sustainable construction is further discussed below. In addition, the study focused on small practices as designated by RIBA (Royal Institute of British Architects), that is, firms with fewer than 10 employees. Small architectural practices tend to focus on residential work, and on refurbishment and extension of existing dwellings in particular (RIBA 2014). With an estimated $87 \%$ of housing stock for 2050 already built (Boardman 2007), these architects are crucial to the minimisation of the environmental impact of current and future housing. However, there had been relatively little research in this domain and the current study aimed to address this gap.

With a focus on small practices, the literature on small businesses and sustainability was explored. This literature assumes a degree of commonality in the opportunities and constraints for small firms across sectors. With respect to sustainability, the literature has tended to examine or analyse 'barriers' and 'drivers'. In a seminal collection of studies on SMEs and the environment edited by Hillary (2000), common barriers have been described across small and medium-sized enterprises in sectors as diverse as mechanical engineering, refrigeration, printing, baking and business services. These barriers include lack of resources, especially time, and lack of knowledge and training (Smith, Kemp and Duff 2000, Tilley 2000); absence of demand by customers and lack of legislation (Gerstenfeld and Roberts 2000, Petts 2000, Tilley 2000, Hillary 2004). A more recent review of 33 studies on uptake of environmental management systems by SMEs noted an assumption of increased costs by SME managers, again with the absence of legislation and limited market demand as major barriers (Hillary 2004, Simpson, Taylor and Barker 2004). However, in a study of over 100 Australian SMEs (Gadenne, Kennedy and Mckeiver 2009), it was argued that few 
small firms demonstrated capability to communicate their environmental engagement effectively, in order to derive competitive advantage, suggesting an interaction between factors within the firm and external influences. In parallel, drivers have been deemed to include legislation, competitiveness, customer demand and stakeholder pressure (Gerstenfeld and Roberts 2000, Hillary 2000, Tan, Shen and Yao 2011). Argument has been made for the need to pressure SMEs into greater action on sustainability, via regulation and market forces (Bianchi and Noci 1998). In some of the few studies with SMEs in construction, the role of the client in driving sustainability has been emphasised (Revell and Blackburn 2005, Revell 2007). From these studies, the primary drivers of regulation and market demand have been classified as external influences (Hillary, 2004; van Hemel \& Cramer 2002) but other research has suggested that factors within the organisation may be more important. Van Hemel and Cramer (2002), in an intensive exploration of eco-design with 77 Dutch SMEs, found internal drivers for improved environmental performance included cost reduction, improved image, new market opportunities, commercial benefits and opportunities for innovation. Beyond these internal business drivers, factors which relate to people within the firm have emerged in research. Even two decades ago, environmental concern, measured as attitudes to energy efficiency, waste minimisation and business responsibility towards the environment, was found to be very high among SME owner-managers (Merritt 1998, Petts, Herts and O'hEocha 1998). A large, multi-method study of SMEs in eastern and mid-England found that compliance with environmental legislation appeared to be driven primarily by personal moral conviction (Petts 2000). Hillary's (2004) frequently-cited review of UK and European studies on SMEs argued that negative management attitudes may be a potential barrier to implementation of environmental management. In a study investigating seven cases of SMEs who were in the process of implementing an environmental management system, Palmer (2000) found that all had one or more individuals in positions of power driving the change, in most cases the owner manager, and that cost-savings did not appear to be a motive. The potential for substantive influence of 'green champions' on work colleagues is well evidenced, the term 'green champion' being used for an individual in the 
workplace who is personally committed to pro-environmental actions (Vickers 1999, Walley 2000). Where the 'green champion' is also a manager, the potential for spreading influence on environmental matters can be even greater (Graves, Sarkis and Zhu 2013). A qualitative study of 39 small businesses in the hospitality sector, who were part of a green accreditation scheme, argued that personal values and ethics were a primary determinant of the businesses' engagement with environmental sustainability (Tzschentke, Kirk and Lynch 2008). Reviewing previous research on managers of small firms, Roxas and Coetzer (2012: 463) noted: "beliefs, values, attitudes and strategic mental models of the owner-managers ultimately determine the strategic direction, configurations and practices of the firm". Cassells and Lewis (2011) usefully summarise findings of influences on SMEs and environmental responsibility as driven by financial motives (such as cost reduction), compliance motives (such as avoiding fines for non-compliance with regulation) and personal motives (such as the owner-manager's values).

Moving from empirical to theoretical understanding, a useful framework within which to position such findings is that of Bronfenbrenner (1977), who categorised five levels of influence on human development and, ultimately, human behaviour. Adapting Bronfenbrenner's ecological theory to the domain of sustainable construction, we can define the levels in the model as follows. The broadest level is the macro, which includes national and global economies and nation culture. The exo level comprises organisations, markets, regulation and other similar social institutions. The meso level can be interpreted as interactions between organisations within the supply chain: business networks, supplier networks and client networks. The micro level comprises face-to-face influences on a daily basis: clients, employees and suppliers. Finally, there is the individual layer in which psychological factors including personal norms and motivations influence behaviour. The ecological model proposes that all layers shape human action, which suggests the need for research to examine all levels of influence on environmentally-impacting behaviour. However, the literature has tended to focus predominantly the exo and meso levels, that is, on market dynamics, legislation and customer demand as well as technology, and less attention has been paid to micro and 
individual level. Few studies have investigated individual psychological factors despite the pivotal role of the individual professional making day-to-day and longer-term decisions on construction projects. A similar point has been argued by Henn and Hoffman (2008) who noted that the framings of sustainable construction have tended to be economic as well as technical/material but the social and psychological implications of change have not been explored to an equivalent extent. Janda and Killip (2013) have argued that research has omitted the 'human intermediaries' who mediate between technology and client, that is, the building industry professionals. Bronfenbrenner's model is drawn on here to map previous research and to specify the focus of the current study at the individual level of analysis.

In psychological terms, Bronfenbrenner's ecological model maps influences on behaviour from the distal or distant (e.g. national economy) through to the proximal (e.g. owner-manager's motivation). It is the proximal which tends to predominate as a more immediate influence on what an individual chooses to do. That is to say, it is proximal factors which are more likely to have a bearing on the day-to-day decisions and actions in the work context of an architect in a small practice. The gaps on social and psychological factors pointed to by Henn and Hoffman are therefore particularly important to address in order to understand how individual professionals in construction can change how they operate and thus how wider change in the industry may be brought about (Sunding and Ekholm 2015).

\section{Definitions of sustainable construction and design}

In a widely cited definition, sustainable construction has been characterised as the creation of healthy, resource-efficient buildings designed from ecological principles (Kibert 1994). BREEAM (Building Research Establishment Environmental Assessment Method), one of the leading and most comprehensive systems for rating the environmental impact of buildings (Lee 2013), evaluates performance in nine domains, including energy and materials. Assessment is conducted on design and construction, as well as a separate assessment for buildings in use. The Passivhaus standard for new and refurbished dwellings, increasingly adopted in the UK, sets stringent requirements on 
heating demand, achievable through super insulation and very high airtightness. The UK Government's Strategy for Sustainable Construction addresses carbon dioxide reduction, in addition to climate change resilience, water, biodiversity, waste and materials (HM Government 2008). A common theme in each of these interpretations of sustainable construction is the important role of design. Indeed, the Strategy for Sustainable Construction deems good design as synonymous with sustainability (HM Government 2008). The engagement of architectural designers, then, is a crucial aspect of expanding sustainability in construction. Within European policy, the concept of eco-design has been developed over the last 20 years. Although targeted at product design, the principles can equally apply to construction design, and include the use of low impact material, reduction of material use, optimisation of production (construction) techniques, reduction of impact during use, optimisation of product (building) lifespan and optimisation of end-of-life processes (demolition) (Van Hemel and Brezet 1997, Vallet et al. 2013). These principles of eco-design provided an appropriate framework of understanding of sustainability in construction design for the current study.

\section{People's engagement with environmental sustainability}

Janda and Killips (2013) asserted that "professionals are people too" and the psychology literature has explored what is known about people and their engagement with the environmental agenda. Drawing together twenty years of research and theory on determinants of human action, Stern and colleagues (1999) proposed the value-belief-norm (VBN) theory of environmentally significant behaviour. VBN theory posits that personal values contribute to beliefs relating to environmental concerns, these beliefs inform personal moral norms and such norms guide environmentally-impacting actions. Personal values or guiding principles for an individual's behaviour have been extensively explored (Schwartz 1992) and there is strong empirical evidence for three underlying dimensions: altruistic (concern for other people), egoistic (concern for status, achievement and power) and biospheric (concern for the natural world). VBN theory posits that the relationship between values and behaviour is mediated by (works via) beliefs including awareness of 
the consequences of inaction to personally important objects and awareness of one's own responsibility to take action. Thus personal moral norms develop from the knowledge that there are environmental threats to the things that one values and that one can act to mitigate the threat. As an empirically evidenced synthesis of earlier theories, VBN theory demonstrates the role of a personal sense of morality or moral norm in driving pro-environmental behaviour (Stern 2000). It should be noted that the theory does not suggest that human behaviour can be ascribed solely to values, beliefs and norms: Stern (2000) describes a wider theoretical framework in which environmentally significant behaviour is understood to be influenced by external contexts, such as legislation and social and physical infrastructures which can be related back to Bronfenbrenner's ecological model. Nonetheless, evidence in support of VBN theory demonstrates that individual dispositional factors such as values and norms influence environmental behaviours (Steg, Dreijerink and Abrahamse 2005, Abrahamse and Steg 2011).

In the previous explanation, the terms 'pro-environmental behaviour' and 'environmentally significant/impacting behaviour' were both used but there is a crucial difference between them (Gatersleben 2013). Pro-environmental behaviour is defined as behaviour which is intended to minimise harm to the natural world (Kollmuss and Agyeman 2002). Environmentally significant behaviour on the other hand is any behaviour which may cause (adverse or beneficial) impact, whether or not this is intended. Thus specifying thermal insulation levels in a building design is environmentally significant; seeking to maximise insulation for greater energy efficiency may be proenvironmental. VBN therefore addresses only behaviour that is intentionally pro-environmental, but this is a subset of human activity that is environmentally significant. Thus a wider theory of the drivers of human behaviour is needed.

\section{Motivation Theory}

In psychological theory, motivation is understood as the energising force behind most human action. It determines not only if and what behaviour may be enacted, but also its persistence and duration (Wiener 1992). An apposite theoretical framework for motivation lies in self- 
determination theory (SDT; Ryan and Deci 2000). SDT conceptualises the person as possessing fundamental needs for competence and autonomy, and is therefore particularly relevant for examining the motivations of construction professionals. Individuals are proposed to be innately driven to mastery of their environment, that is, to desire a sense of competence or control over their lives, and to a sense of volition, self-regulation and autonomy in their behaviour. The contexts in which the individual operates can either support or frustrate these basic drives: the business supply chain, the work organisation, the market sector, the national economy (the macro, exo and meso layers of influence) form part of these contexts. Clearly people operate with multiple motivations and SDT proposes that human motivations may be plotted along a bipolar spectrum, ranging from extrinsic or controlled motivations to autonomous or internalised motivations. Controlled motivations are driven from outside the person: financial reward via increased profit and regulation are examples. While controlled motivators can be effective, their effect tends to be limited and motivated behaviour is maintained only while they remain in force. Further, controlled motivations tend to reduce innovation and energy at an individual, and therefore also organisational, level. In contrast, autonomously motivated behaviour is relatively independent of external context, is flexible and volitional. Such behaviours tend to persist longer and to be more resilient in the face of obstacles. Autonomous motivations are experienced as originating within the person, closely linked to psychological factors such as self-identity (one's self-image) and values (what is important to the person). The forms of motivation are not dichotomous and a motivation that initially is extrinsic may over time become internalised. For example, specifying a high level of insulation in a design may be done at first because it is mandated by building regulations but over time, an architect may come to see this as a design detail which s/he always specifies as part of good design practice. Applying these theoretical insights to sustainable design in construction, it can be seen that individuals within the sector may have multiple motivations to engage in environmentally-beneficial activity in their work. However, although autonomous motivations offer a more durable basis for such activities, much of 
the focus of existing research has been on controlled motivators such as market demand and regulation.

Although individuals may have multiple motivations towards becoming more environmentally friendly, equally individuals may not be motivated in this direction. Studies on the extent of people's engagement with sustainability show wide variation in orientation towards the environment (Dunlap et al. 2000), environmental concern (Urban and Scasny 2012), in climate change scepticism (Whitmarsh 2011) and self-reported pro-environmental behaviour (Whitmarsh and O'neill 2010, Urban and Scasny 2012). In addition, even where individuals are motivated to consider their environmental impact, their workplace, business networks and economic contexts may frustrate such motivation, and this may in part explain findings that environmental concern does not necessarily translate in environmental action (Cassells \& Lewis, 2011).

A final concept of note from psychological theory is that of equifinality: the same behaviour may be triggered by a variety of differing motivators. This has been demonstrated at an organisational level (Babiak and Trendafilova 2011) but operates equally at a more individual level. For example, a low-U-value glazing system may be used on a project because of building regulations, because the client requested it, because the architect is familiar with the system, because the architect is seeking to optimise energy efficiency in order to add value for the client, or because the architect is personally committed to minimising environmental impact. Any of these or a combination of several can result in the same outcome. This suggests that environmentally sensitive design may emerge from a number of individual motivations. The research questions therefore were as follows:

- What personal motivations drive architectural designers to pursue environmentally sustainable design in their work?

- Can non-environmental motivations drive sustainable outcomes?

The aim was to explore what drives construction professionals in their work, to examine the relationship between their motivations and sustainability. 


\section{METHOD}

\section{Epistemology and methodology}

Our epistemological stance was towards the centre of Potter and Hepburn's (2005) spectrum from naïve realist to radical relativist. Best defined as critical realist, our stance met their description of overlap with contextual constructionist positions which assume that knowledge is contextual and perspective-dependent. This position led to a qualitative approach to method in which participants' experiences and meanings are focal (Willig 2001). A priori definitions by the researcher are avoided (Willig 2001), the researcher must interpret the data and the lack of researcher subjectivity is acknowledged (Potter and Hepburn 2005). However, lack of subjectivity does not mean lack of validity and many scholars have proposed criteria for evaluating the validity of qualitative research (Henwood and Pidgeon 1992, Yardley 2000, Willig 2001). These scholars propose that the fundamental requirements are reflexivity and context, transparency, rigour, and impact. We have attempted to meet these standards as follows. Reflexivity and context were addressed by detailing the circumstances of the participants (e.g. location, types of projects) and of the researchers. Transparency was addressed by providing a detailed account of the process of analysis and by independent review by the second and third authors of the initial analysis conducted by the first author. Transparency was further addressed through use of extensive data extracts in the findings below, so that the reader can assess the appropriateness of the researchers' interpretations. Rigour has been addressed through completeness of analysis and inclusion of counter-examples. Impact was addressed by considering practical application of the findings. Participant validation (Willig 2001) was also undertaken: one of the study's participants read and commented on the draft paper, with no major issues being raised.

In keeping with our epistemological stance, which assumes that knowledge is constructed, relative and contested, we did not attempt to assess the participants' understanding of sustainable design. Supported by empirical studies such as that of Schweber (2013) for example, who demonstrated how the BREEAM standard is by no means an agreed approach to sustainable 
construction, we accepted participants' understanding of environmental sustainability in design as subjective and contextual. This was appropriate given the focus of the research question on designers' motivation.

\section{Participants and Procedure}

Semi-structured interviews and inductive thematic analysis were chosen as appropriate for the methodological approach. The unit of analysis was the individual. Twenty-eight professionals with responsibility for design, in 14 small firms, were interviewed. Two-thirds of the participants were recruited through professional and personal networks, with the remainder recruited from an online industry database. The interviews were conducted as part of a project offering basic training in ecodesign to SMEs in construction so the recruitment criteria were architectural designers in small businesses who were interested in learning about eco-design. The participants therefore considered themselves as non-expert in sustainability. None of the firms had ISO14001 or equivalent accreditation and only three emphasised sustainability on their websites. The participants were all based in the Greater London area. Two of the businesses offered structural engineering services and the remainder provided architectural design services. In the architectural practices, all but three of the participants were registered architects. The remaining three had architectural qualifications but were not yet registered and therefore in the UK cannot entitle themselves as 'architects'. We use the term 'architectural designer' here as an inclusive term to encompass all of the participants, each of whom had profession responsibility for construction design in some form. The engineering firms were included in the analysis as one provided a generally negative response to the concept of sustainability in their work, in contrast to the other engineering business and all of the architectural firms. This provided a useful counter-example in the analysis, a requirement for demonstrating rigour in a qualitative method. Quotations from the engineers are identified by En below, and the architects by An. The majority of the participants' work was in the private domestic sector, primarily extensions and refurbishments as well as new build, with some larger projects in the education, commercial and residential development sectors, ranging in value from about $£ 30,000$ to $£ 3$ million. 
The interviews were conducted by the lead author, lasted between one and two hours and were audio-recorded and transcribed verbatim. The interview session was structured as follows: factual questions on size of business and type of project, open questions to elicit attitudes and views on becoming more sustainable, eco-design training, and questions on motivation in work.

\section{Analytic Procedure}

Thematic analysis was selected as an appropriate analytic method. Thematic analysis allows a two-level reading of the text, firstly at a level which reflects the immediate meanings and secondly at a critical analytic level, in which patterns in the data and links external to the data to previous theory and literature, can be explored. This analytic method facilitates movement beyond the descriptive and beyond a realist approach, harnessing apposite theoretical perspectives to gain deeper understanding. Adhering to the well-established methodological guidelines of Braun and Clarke (2006), analysis proceeded by familiarisation with the texts through reading and re-reading, coding each segment that related to motivations around sustainability and to motivations more generally. Coded segments were then clustered into themes, repeatedly checked back to the text to ensure completeness and context, and data extracts were then collated within the thematic headings. The analysis was conducted by the first author, who is an environmental psychologist and experienced qualitative researcher. The major themes were then presented for independent verification to the second and third authors, respectively a senior academic in construction and a qualified architect with experience operating a small architectural design practice. No major issues were identified in this review. The next section presents the major themes. Within each theme, the general pattern of responses is first described, followed by an analytical discussion. Extensive data extracts are provided to demonstrate transparency and rigour, and to allow the reader to assess the analytic claims. 


\section{FINDINGS}

\section{Motivations for Sustainable Design}

\section{Client Demand}

When asked about sustainability in their work, the first driver to which many of the participants referred was client demand. In most cases, the client was the private homeowner, although participant also referred to commercial clients such as developer organisations. For example, Architect A4 said: "The main impetus always seems to be client-led in my experience". However, most of the participants had seen little requirement from their clients:

"Except in the very rare, and I can probably count on one hand case, where the client is very environmentally aware and is very keen to use products of certain credentials and therefore it's effectively imposed upon us rather than the other way round." [E1]

This quotation carries an interesting implication that it could or perhaps should be "the other way round", with the initiative coming from the designer, and indeed this more nuanced balance was evident across a number of interviews. Architect A4, who had begun by pointing to the customer as the driver, went on to say: "If you think there's an opportunity through passive design...then you should [include it] because they're [i.e. the clients] not going to ask you to do it". Here the initiative for improved environmental sustainability originated with the professional rather than the client, and several designers spoke about influencing or guiding the client towards sustainability. There were further examples of where the architectural designers had gone beyond the client brief to try to include more within the design that would enhance comfort and warmth, as well as aesthetic value: for example, "it is about money...but it's also about comfort and creating a home" [A9].

From the theoretical perspective of SDT, client demand can be understood initially as an extrinsic motivator, with the assumptions that the designers must satisfy the client requirement in order to earn their fees on the project and to establish the basis for future business. However, the recognition that the design professionals go beyond what is asked in the brief to add further value to 
the client suggests that internalised motivations are also involved. There was evidence in many interviews that the designers tended to draw on their experience of what the client needed, above and beyond what was included in the brief, to develop enhanced designs, from considering the householder's budget for a small extension to designing for the property developer's desired market. In meeting client demand then, the architectural designers were not only extrinsically motivated. Of interest to the research question on sustainability was the finding that some of the enhancements to design had clear environmental benefits, as well as offering increased value to the client, such as improved insulation providing better energy efficiency as well as enhanced warmth.

It is important to note that motivation may be reciprocal between architect and client. Client demand may act as an extrinsic motivator for the architect, similarly the architect may represent an external motivating force to the client. The architect may draw the client's attention to regulatory requirements or to incentive schemes, such as BREEAM or feed-in-tariffs, and thus act as a conduit for institutional motivators. Alternatively, in seeking to influence the client, the architect may suggest other extrinsic motivators for the client such as lower energy bills through increased levels of insulation. Previous research has examined the role of incentive schemes in motivating households to implement energy efficiency measures (Mallaburn and Eyre 2014). Here our focus is on the motivators for the architectural designers, the extrinsic and intrinsic factors that encourage their engagement with sustainable design and drive their professional work more generally.

\section{Regulation}

A second common theme emerging from the participants' responses on sustainability was that of regulation. Most of the participants viewed regulation positively and agreed that "legislative drivers are a good thing" [E2]. One said "[Sustainable design] has to become regulation for us as architects to help our clients" [A10], suggesting that legislation can act, not only as a direct driver of architects to design more sustainably, but also as a way in which the architect can influence the client. For example, another explained: 
"Planning policy works...we'd like to put green roofs on 'cause we think they look cool...and it feels like the right thing to do and we can now say, 'well, you have to have it, the planners have said that you have to have it"' [A18].

Here the designer's motivations appear to relate to aesthetics and an ethical perspective, and planning regulation then supports these autonomous motivations in order to drive the client.

Self-determination theory argues that extrinsic motivators can be limited in effect and there was evidence here to support this proposition. Extrinsic motivations lend themselves to minimal effort to comply ("I'm well aware that there's many window manufacturers that can do a lot better than [the latest building regulations] as a matter of course" [A2]) and attempts to avoid compliance ("Any discussion [the clients] have is around usually [laughs] how to get round the new regulations" [E6]). Although these examples relate to the response of others in the construction supply chain (the client, the manufacturer), it can be suggested that extrinsic motivators such as regulation may also have a similar influence on some architects.

\section{BREEAM}

A further extrinsic motivator that may be expected to influence sustainable design is BREEAM accreditation. A BREEAM 'outstanding' or 'excellent' rating could act as an external 'reward' for design professionals, providing visible recognition of achievement. However, BREEAM was mentioned in only four interviews. One participant saw the advantage of an external assessor taking some of the responsibility for sustainability away from the designer. Two others described it as a 'tick-box' exercise. Equally, Passivhaus certification, which could also act as an extrinsic motivator for architectural designers, did not feature in the participants' responses. Thus, for these participants, BREEAM appeared to be a largely ineffective extrinsic motivator, either irrelevant or subject to the theoretically predicted flaws of controlled motivation, which encourages lack of personal responsibility and involvement and minimally acceptable compliance. 


\section{Moral Imperative}

Several designers noted an ethical aspect to sustainable design. One said "It's wrong to do nothing. You've got to do something and you've got to think about what you're doing" [A4]. Referring to the decision to act as right versus wrong invokes a moral dimension and even a moral imperative. It appeared that some participants had gradually realised their own role and responsibility:

"It's only in the last couple of years that I've really started to think, 'Actually got to start doing something about this,' rather than carrying on writing out Celotex on my drawings, you know, actually do something" [A15].

These viewpoints illustrate the propositions of value-belief-norm theory (Stern et al. 1999), that personal moral norms can guide pro-environmental behaviour and that an awareness of the consequences of doing nothing and of a personal responsibility to take action are prerequisites in the formation of personal norms.

Value-belief-norm theory further suggests that beliefs influence the development of moral norms and there was evidence in the interviews of negative as well as positive beliefs and attitudes around sustainable design. Of the 14 participating practices, only one expressed predominantly negative beliefs, including lack of knowledge, perceived difficulty and assumption of increased cost and reduced availability of sustainable materials. In other firms, participants raised concerns that clients will always seek the cheapest option and choose minimal compliance with legislation. Negative beliefs such as these could be seen to frustrate autonomous motivation towards sustainable design, and they demonstrate one way in which the macro, exo and meso layers can impinge on day-to-day decisions and actions. In contrast, another architect took a robustly positive approach:

"It's a very similar strategy that we have [with sustainability as] with actually planning which is we're always pushing the boundaries, because if you sit and say, 'Well we're just going to have that little box.' Yeah, you know you're going to get 
that, that's fine... but if you start going bigger and taller then you might not get all of that but you're going to get a hell of a lot more than if you just accepted the little box. So I think it's a very similar sort of process and thinking [for sustainable design]. If you think about it that you push as hard as you can and then you might end up losing half of what you've put forward, but at least you're going to get half more than if you didn't bother at all." [A8]

This speaker saw similarities between sustainability in design and other design aims. As with perhaps all architectural designers, her practice routinely dealt with constraints - planning constraints are mentioned in the extract. However, she took the view that attempting to 'push the boundaries' resulted in greater success. Her positive approach would seem to facilitate motivation towards sustainability. Comparing her approach with the practice which expressed a number of negative beliefs provides an example of how, given similar macro, exo and meso layers of influence, the actions taken in business are still strongly influenced by the psychological processes of the individual professional.

\section{Personal Commitment}

Some participants linked their interest in sustainable design explicitly to their self-identity, speaking about being "passionate about recycling at home...Because I as a person am environmentally conscious" [E1] and the pervasiveness of their thinking about sustainability: "It is always in the back of my mind because I am personally interested in the environment generally" [A3]. Whereas the quotation from the first participant here (E1) indicates the potential for his 'green' identity to influence his work, in the second example (A3), the designer acknowledges that her personal commitment to the reducing environmental impact is a motivator in her designs. When speaking about sustainability in their work, aspects of their professional identity as architects and engineers were evident for some participants and this is discussed further below.

Motivations experienced as stemming from and highly congruent with self-identity fall clearly within the range of autonomous drivers of behaviour. So there was a close alignment 
between their designs and their sense of self-identity for the participant architectural designers, and for some, their interest in sustainability was a further aspect of self-identity motivating their work.

\section{Other Motivations}

Cognisant of the principles of equifinality, that multiple motives can contribute to the same outcome, the participants were asked what motivated them in their work and other salient motivations are now explored.

\section{Self-identity}

In many ways, the designers' motivations appeared closely linked to self-identity, that is, who they saw themselves as being, and this emerged in a variety of ways.

One participant said: "My new model is that I will do a very nice job...I've done too much mediocre work during the recession. I'm not prepared to do it anymore...It's got to be high quality work" [A14]. In this, he appeared to be expressing his self-identity, defining who he was by what he rejected in his design work. In many of the responses, a professional identity was in evidence, in which several participants explicitly referred to themselves as architects and as professionals.

There was a strong sense of ownership of their designs:

"I remember when I used to work out on site and at the end of the day I could walk off and say 'do you know what, I built that today' ... and it's really rewarding" [E1] In describing his motivation, another participant said "I own all this and I get to finish it" [A4]. One participant mentioned the "ego and vanity" of some of his earlier designs [A14] and another recognised the extent to which she identified with her design work: "When you're designing something, you don't think of someone pulling it down, because that would hurt, wouldn't it?" [A3]. Suggesting that damage to a building would be experienced as physical or emotional pain to the designer demonstrates the extent to which architects can invest the self in their designs. The outcome of their design process can be experienced as an extension of the physical self. This point on the relationship between their self-identity and their designs was made clear in a reflection by 
A18: "I think there's a tendency in architecture, 'cause the nature of architects being who we are, we like things to have an enormous legacy." In this extract, the speaker refers to his identity as part of a profession or a group of people ("who we are") and the extent to which the work of architects, the end-product of design and building, helps to construct that identity. For some participants, the concept of sustainable construction was linked explicitly to their professional identity:

"...every time we design, we need to make sure that we bring some sustainable solutions for our design. That's, as a professional, we all agree on this" [A19].

\section{Quality in design}

A common theme in the responses was that of quality in design. The discussion above described how the designers appeared to go beyond the client's brief and how the evidence strongly suggested motivations from client demand have become internalised. Going beyond what is needed implies more autonomous motivation. Further, there was a sense of pursuit of quality for its own sake, not simply to satisfy the client. The participant who said: "It's got to be high quality work" [A14] suggested high personal standards guided his approach to his designs.

In a number of accounts, sustainable design appeared to align with quality in design. The architects described sustainable design as "designing responsibly" [A9] and using "proper architectural principles" [A18]. As one participant summarised it, "the issue is about the quality of the design, rather than the end result of its U value" [A17]. Thus the participants pursued high quality in their designs as an autonomous motivation, and some recognised ways in which designing for sustainability was part of pursuing design quality.

\section{Enjoyment}

In addition to deriving a sense of self-identity and pursuing quality in design, the designers' motivations in their work also centred on enjoyment. Several spoke of enjoying what they do: "I think we're fortunate insofar as we do enjoy what we do... I love coming to work in the morning." [E1]. Specifically for some, it was the creative process which they particularly enjoyed. Participant A2 explained: "We often say that there's a kind of flow in actually drawing a design, when you're 
actually into a drawing and doing it, there's something quite satisfying, cathartic." For others, it was the tangible nature of the outcome that carried the most positive emotions: "For me the tangibility of it is massive."[E1] The participants gained satisfaction and enjoyment from the creative aspects of their work, from the satisfaction of the design process itself and from their involvement in the creation of material artefacts. These are typical forms of intrinsic motivations, in which reward is gained from the nature of the activity.

\section{Impact on People}

A perhaps less expected motivation was the awareness of the impact of their work on other people. Describing a specific current project, Participant A14 said "I'm very aware that they're putting everything into it. We have to borrow some money". He begins this extract by talking about the clients ("they") but moves on to acknowledge the joint nature of the project ("we"), clearly putting himself into his client's shoes and demonstrating not only his recognition of the impact of the project on the client but also the extent to which he had internalised the client's perspective. There was awareness of influence which extended far beyond the design and construction stages. For example, Architect A3 described her primary motivation as "making buildings work for people". Another acknowledged the longevity of the architect's impact and positioned it as a major motivator in architectural design:

"You're making such a huge choice and influence... It basically shapes everything we do. And then we're just making really quick decisions that will affect people for a vast majority of their life." [A1]

This acknowledgement of influence on the lives of their clients, continuing well into the future, was evident in a number of the accounts and appears to speak to a sense of professional responsibility. Pay

In addition to self-identity, quality in design and enjoyment as motivation for their work, a few participants mentioned pay and, interestingly in this small set of participants, it was introduced by the engineers and not the architects. This may reflect the relatively poor financial reward for 
architects compared to other professions, noted by Caven and Diop (2012). For one of the engineers, work is "just something you've got to do isn't it?" [E5]. However, he also noted that he usually enjoyed his work. Thus pay as an extrinsic motivator was salient for a few participants although most referred to multiple motives which included self-determined motivations, in accordance with motivation theory. No link was evident between pay and sustainable design. As 14 of the participants were owner-managers of small firms, it could be expected that business development through incorporation of sustainable design could act as an extrinsic motivator. However, a separate analysis of marketing strategy by the firms here concluded that most failed to recognise the marketing potential of sustainable design (paper in press, ref to be added after review) and none made reference to marketing, business or financial benefits of sustainable design.

\section{DISCUSSION}

Addressing the paucity of social science research on sustainability in construction, a novel approach was adopted in applying insights from psychological theory to examine the relationship of the motivations of architectural designers to inclusion of principles of environmental sustainability in their work. Building on previous discussion of the impact of personal motivations on the operation of SMEs, 28 individuals were interviewed who offered architectural design services across 14 small firms. Motivations driving sustainability in their designs included client demand, to a limited extent, and regulation, and for some, personal commitment and a moral imperative was in evidence. Other motivations included self-identity, pursuit of quality in design, enjoyment and awareness of impact on people, and for some these motivations could be linked to incorporation of sustainability principles in their designs. Applying self-determination theory (Ryan \& Deci 2000), we conclude that autonomous motivations predominated over extrinsic or controlled motivations, that is, that more motivations emerging from individuals themselves appeared salient than external factors such as regulation and market in influencing sustainability in their design work.

Although client demand as an extrinsic motivator was the first driver to which most participants referred, the discussions then elaborated that, in fact, they perceived little demand 
from clients to consider environmental sustainability in their designs. Further, it emerged that, in many instances, the architectural designers themselves were the driving force and were instigating the inclusion of sustainability principles or guiding clients towards greater sustainability. This lends support to the argument of Cohen et al. (2005:783) that “It's the architect's job to convince the client that they want things", albeit being achieved by the participants here in a more subtle manner than that suggested by Cohen. Self-determination theory posits that extrinsic motivators may over time become internalised (Ryan and Deci 2000). It could be argued that the designers' inclusion of sustainability was, in part, driven by internalisation. This aligns with further evidence in the interviews of the designers going beyond the client's brief, drawing on their experience and expertise to add additional value to the end-product.

BREEAM or similar certification schemes did not appear to function as a motivator for the designers interviewed. However, regulation emerged from most discussions as an important, and generally favoured, driver of more sustainable design, echoing the calls of other scholars for greater regulation (Henn and Hoffman 2013, Rajkovich, Kwok and Larsen 2013). Clearly, regulation can operate as an effective extrinsic motivator. However, there are risks with such controlled motivation. Taking an economic perspective, Frey (1997) demonstrated that regulation can be counter-effective and can undermine autonomous motivations. Discourse around regulation for improved environmental sustainability in the absence of accompanying discussion of the moral imperative can result in a 'box ticking' mentality, as was in evidence here. It can lead to effort to try to work-around or avoid the requirement as participants noted. It may also lead to abdication of responsibility or minimal compliance. As was shown above, even where a participant was in favour of BREEAM, it was associated with shifting responsibility away from the designer. Thus dependence on extrinsic motivators alone is a risky approach with which to promote change.

For some of the participants, pursuit of sustainability in their design had an ethical or moral dimension: they felt that sustainability should be incorporated, by themselves and other architects, as the right thing to do. This can be understood as an activated personal norm or moral obligation, 
which has been shown to contribute to pro-environmental behaviour (Stern et al. 1999). This speaks to professional as well as personal pride: these participants had realised their influential role and in fact their responsibility to try to make changes. The importance of the personal conviction of the architect has been noted previously (Blau 1984), as has the moral responsibility of designers (Farmer and Guy 2010). More generally, personal ethics have been argued to influence professional ethics (Quinn 1997). Beyond a moral motivation, some of the participants described having a personal commitment to sustainability, that is, their self-identity was connected to behaving proenvironmentally. Motives experienced as based on injunctive societal norms ('I'm doing this because I should') may form an early step in internalisation while motives experienced as associated with self-identity are more deeply internalised (Ryan and Deci 2000). In sum, considering motivations which were related directly to consideration of sustainability in designs, internalised or autonomous drivers appeared to predominate.

Beyond motivations with a direct relationship to sustainability were other autonomous motivations which, we argue, appeared to link indirectly to environmentally-beneficial design. The participants provided interesting references to the extent to which their self-identity, and that of architects in general, was bound up in their designs, a finding previously noted in Caven and Diop's (2012) study of architects. The participants spoke of ownership, of vanity and ego, of feeling hurt at the thought of destruction of their design. A telling point was made on the general desire of architects to leave a lasting legacy. Sustainability goals of durability, designing for re-use and extended life for buildings aligns closely with desires for legacy. A strong professional identity is likely to contribute to powerful motivations to provide an excellent service, to demonstrate and develop expertise and to be proud of one's contribution to the public good (Morell 2015). The connections between such motivations and sustainability in construction are clear: sustainable design demands high standards, requires development of technical expertise and is now a requirement for the industry to minimise its socially and environmentally damaging impacts. Caven and Diop (2012), as well as Cohen and colleagues (2005), noted further that creativity contributed to 
architects' professional identity, and they suggested that both professional identity and creativity are "intrinsic rewards" in the profession - what self-determination theory would term 'autonomous motivations'. Creativity arose also in the findings here and was related to enjoyment of work. A relevant insight from self-determination theory is that autonomous motivation in the workplace contributes to creativity and innovation (Gagné and Deci 2005) whereas controlled motivation tends to diminish creative capacity (Ariely et al. 2009), a theoretical insight of importance for both architectural design in general and sustainable construction in particular. An architect who feels compelled by regulation to include sustainability features, for example, may be less creative in pursuit of a solution than an architect who is pursuing sustainability for self-initiated motives.

Participants appeared to connect creativity, and their enjoyment of this aspect of their work, to quality in design. Although quality of product lends itself to commercial value (Baker and Lamb 1994), here the participants' focus was specifically on design rather than quality as a marketing strategy. Indeed, a separate analysis of marketing strategy by the firms who participated in this study found that most failed to recognise the marketing potential and actual marketing role of sustainable design in their business development (paper in press, ref to be added after review). Given the emphasis in architectural education on the Vitruvian ideals of designing for soundness, usefulness and beauty, perhaps unsurprisingly, a number of participants linked high quality in design with sustainability, suggesting that pursuit of design quality is congruent with pursuit of improved sustainability. Passive heat and ventilation management and selection of materials optimised with consideration of provenance, toxicity and longevity, for example, can link to quality in design.

A final autonomous motivation that was evident in the data was that of impact on people. The participants readily discussed their awareness of the effect of the outcomes of their work on individuals and how this was a driver for their design. Their comments centred primarily round the impact on clients. Morell (2015), Duffy and Rabeneck (2012) and others have argued that a defining feature of the professional is their responsibility to the greater public good. Thus there is potential for broadening the perspective of impact on people to that of society in general, nationally and 
globally, and current and future generations, as encapsulated in Brundtland's definition of sustainability (WCED 1987).

For the group of professionals interviewed then, beyond the extrinsic motivations of regulation and, to a much lesser extent, client demand, their own self-determined motivations were related directly, or could be related indirectly, to increased incorporation of sustainability in design.

As with all research, there were limitations in the study design. Although we did not collect data on the age of the participants, the interviews touched on the extent of their formal education in sustainable design and this varied considerably. A qualitative approach cannot suggest how widespread the findings may be for a wider population. As the participants had volunteered to undertake basic training in eco-design, they were neither expert in sustainability nor disengaged from the environmental agenda. The findings therefore may not apply to architectural practices who specialise in sustainable design nor to architectural designers who have no interest in environmental sustainability.

\section{CONCLUSIONS}

The study took a novel approach to understanding why sustainable design may be practised by architectural designers, and what scope exists to change behaviour towards greater sustainability, by examining individual motivations from the perspective of psychological theory. Acknowledging that action in the construction industry is influenced by a wide range of forces such as national economy, legislation and market demands, it is argued that individual decision making - and therefore individual psychological processes - also affect what happens in the sector. The influence of regulation and client demand was noted in driving engagement with sustainable design. In addition, autonomous motivations of personal commitment and an ethical imperative, as well as self-identity, pursuit of quality and awareness of impact on people, were found to be more salient drivers of sustainability in design.

The participants here provided evidence for the effectiveness of regulation in driving behaviour. However, given the current failure of policy progress in the UK, where instruments to 
drive energy efficiency in new build homes and to stimulate retrofit demand have been revoked in Summer 2015, we argue that it is more important than ever to examine all relevant perspectives which have a bearing on action for sustainability - the improvements required of the industry cannot wait on fickle policy. Further, theoretical understanding of extrinsic or controlled motivations points to the counter-effective risks of regulation: people may become motivated to avoid or to work around legislative requirements, to offer minimal compliance or to abdicate responsibility. Creativity may be constrained and autonomous motivation may be undermined. Anticipation of and dependence on regulatory changes is too risky as the sole approach to move the industry to greatly improved sustainability. Engaging construction professionals can enable more innovative, persistent and deeper change. Construction professionals can be effective change agents (Janda and Parag 2013) and designers in particular have been proposed as potentially important agents of change (Farmer and Guy 2010).

The autonomous motivations in evidence in the participants' responses, specifically self- and professional identity, pursuit of design quality and recognition of the impact of architectural design on people, connect directly and indirectly to the goals of sustainable design. However, the connection between sustainability and autonomous motivations is not necessarily automatic. We suggest three routes through which the association can be made more salient. Firstly, through education: professional identity is developed over time through socialisation processes beginning in professional education (Imrie and Street 2014). Although the code of conduct for UK architects includes one short principle referring to the environmental impact of design (Architects Registration Board, 2010), there is a need to enhance curricula to embed sustainability goals more deeply into the everyday practice of design, to focus for example on the impact on the global community of the built environment in every context, and the careful selection of materials considering provenance and recyclability as well as functional criteria. Secondly, through ongoing professional development in CPD (continuing professional development) and in-house training: organisations and professional bodies could require technical expertise in sustainable design as an indicator of seniority and as a 
criterion for promotion. Finally, in professional discourses more generally: in communications on blogs and social media, in newsletters and publications, from those within the sector and from professional bodies, greater emphasis could be placed on the responsibility of construction professionals to deliver more sustainable buildings and that value to the client now requires consideration of sustainability. These approaches build from the arguments of Dent and Whitehead (2002), Cohen and colleagues (2005) and others that professional identities are framed and constructed in discourse. That is, understanding of what it means to be a professional develops through discussion. Such discourses in education and beyond would both tap autonomous motivations around professional and self-identity and drive greater internalisation, on design quality, on exceeding client expectation and on creativity. Designing for sustainability could increasingly become business-as-usual, meeting a diversity of motivations, rather than an oftencontested, environment-specific 'add-on'.

The focus here has been on positive motivation for sustainability and positive motivations in work more generally but this is not to suggest that all individuals are motivated to become more environmentally sustainable. Indeed, attitudes from the participants were not uniformly positive and this is likely to reflect the sector more widely. By associating sustainability goals with autonomous motivations, discourses come to be not only about climate change or the environment but more fundamentally a part of what people want to do each day. In this way, the reach of sustainable design may be extended beyond those who have a personal interest and commitment to the environmental agenda.

\section{References}

Abrahamse, W and Steg, L (2011) Factors related to household energy use and intention to reduce it: The role of psychological and socio-demographic variables. Human Ecology Review, 18(1). Architects Registration Board Code of conduct. http://www.arb.org.uk/code-of-conduct-2010. Date accessed 26 Feb 2016.

Ariely, D, Gneezy, U, Loewenstein, G and Mazar, N (2009) Large stakes and big mistakes. Review of Economic Studies, 76(2), 451-69. 
Babiak, K and Trendafilova, S (2011) Csr and environmental responsibility: Motives and pressures to adopt green management practices. Corporate Social Responsibility and Environmental Management, 18(1), 11-24.

Baker, J and Lamb, C W (1994) Measuring architectural design service quality. Journal of professional services marketing, 10(1), 89-106.

Bianchi, R and Noci, G (1998) "Greening" SMEs' competitiveness. Small business economics, 11, 26981.

Blau, J R (1984) Architects and firms. Boston, MA: MIT Press.

Boardman, B (2007) Examining the carbon agenda via the $40 \%$ house scenario. Building Research and Information, 35(4), 363-75.

Braun, V and Clarke, V (2006) Using thematic analysis in psychology. Qualitative Research in Psychology, 3(2), 77-101.

Bronfenbrenner, U (1977) Toward an experimental ecology of human development. American Psychologist, 32(7), 513-31.

Cassells, S and Lewis, K (2011) SMEs and environmental responsibility: Do actions reflect attitudes? Corporate Social Responsibility and Environmental Management, 18(3), 186-99.

Caven, V and Diop, M (2012) Architecture: A 'rewarding' career? An Anglo-French comparative study of intrinsic rewards in the architecture profession. Construction Management and Economics, 30(7), 513-23.

Clarke, J A, Johnstone, C M, Kelly, N J, Strachan, P A and Tuohy, P (2008) The role of built environment energy efficiency in a sustainable UK energy economy. Energy Policy, 36, 46059.

Cohen, L, Wilkinson, A, Arnold, J and Finn, R (2005) 'Remember i'm the bloody architect!' Work, Employment and Society, 19(4), 775-96.

Davies, D E, Halliday, M E, Mayes, M and Pocock, R L (1997) Attitudes to cycling: A qualitative study and conceptual framework, Wokingham, Berks: Transport Research Laboratory.

Davies, M and Oreszczyn, T (2012) The unintended consequences of decarbonising the built environment: A UK case study. Energy and Buildings, 46, 80-5.

Dent, M and Whitehead, S (2002) Managing professional identities: Knowledge, performativities and the 'new' professional. New York: Routledge.

Duffy, F and Rabeneck, A (2012) Professionalism and architects in the 21st century. Building Research and Information, 41(1), 115-22.

Dunlap, R E, VanLiere, K D, Mertig, A G and Jones, R E (2000) Measuring endorsement of the new ecological paradigm: A revised nep scale. Journal of Social Issues, $\mathbf{5 6 .}$

European Union (2015) Construction and demolition waste (CDW). http://bit.ly/1ERulE1. Date accessed 15 Mar 2016.

Farmer, G and Guy, S (2010) Making morality: Sustainable architecture and the pragmatic imagination. Building Research and Information, 38(4), 368-78.

Frey, B S (1997) Not just for the money: An economic theory of personal motivation. Northampton, MA: Edward Elgar.

Gadenne, D L, Kennedy, J and McKeiver, C (2009) An empirical study of environmental awareness and practices in SMEs. Journal of Business Ethics, 84, 45-63.

Gagne, M and Deci, E L (2005) Self-determination theory and work motivation. Journal of Organizational Behavior, 26(4), 331-62.

Gatersleben, B (2013) Measuring environmental behaviour. In: Steg, L, Van Den Berg, A E and De Groot, J I M (Eds.), Environmental psychology, pp. 131-40. Chichester, UK: John Wiley and Sons Ltd.

Gerstenfeld, A and Roberts, H (2000) Size matters: Barriers and prospects for environmental management in small and medium-sized enterprises. In: Hillary, R (Ed.), Small and mediumsized enterprises and the environment, pp. 106-19. Sheffield: Greenleaf Publishing. 
Graves, L M, Sarkis, J and Zhu, Q (2013) How transformational leadership and employee motivation combine to predict employee pro-environmental behaviours in China. Journal of Environmental Psychology, 35, 81-91.

Halliday, S (2007) Sustainable construction. London: Routledge.

Henn, R L and Hoffman, A J (2013) Constructing green: The social structures of sustainability. Cambridge, MA: The MIT Press.

Henwood, K L and Pidgeon, N F (1992) Qualitative research and psychological theorizing. British Journal of Psychology, 83(1), 97-112.

Hill, R C and Bowen, P (1997) Sustainable construction: Principles and a framework for attainment. Construction Management and Economics, 15(3), 223-39.

Hillary, R (2000) Small and medium-sized enterprises and the environment. Sheffield: Greenleaf Publishing.

Hillary, R (2004) Environment management systems and the smaller enterprise. Journal of Cleaner Production, 12(6), 561-9.

HM Government (2008) Strategy for sustainable construction. http://bit.ly/1WX69ti. Date accessed 15 Mar 2016.

Hoffman, A J and Henn, R L (2008) Overcoming the social and psychological barriers to green building. Organization and Environment, 21(4), 390-419.

Imrie, R and Street, E (2014) Autonomy and the socialisation of architects. The journal of architecture, 19(5), 723-39.

Intergovernmental Panel on Climate Change (2014) Climate change 2014: Synthesis report. Contribution of working groups $i$, ii and iii to the fifth assessment report of the intergovernmental panel on climate change [core writing team, r.K. Pachauri and I.A. Meyer (eds.)]. , Geneva, Switzerland: IPCC.

Janda, K B and Killip, G (2013) Building expertise: Renovation as professional innovation. In: Henn, R L and Hoffman, A J (Eds.), Constructing green: The social structures of sustainability. Cambridge, MA: The MIT Press.

Janda, K B and Parag, Y (2013) A middle-out approach for improving energy performance in buildings. Building Research and Information, 41(1), 39-50.

Kibert, C J (1994) Kibert, C J (Ed.), Proceedings of the First International Conference on Sustainable Construction, 6-9 November, Tampa, Florida.

Kibert, C J (2007) The next generation of sustainable construction. Building Research and Information, 35(6), 595-601.

Kollmuss, A and Agyeman, J (2002) Mind the gap: Why people act environmentally and what are the barriers to pro-environmental behavior? Environmental Education research, 8(3), 239-60.

Lee, W L (2013) A comprehensive review of metrics of building environmental assessment schemes. Energy and Buildings, 62, 403-13.

Mallaburn, P S and Eyre, N (2014) Lessons from energy efficiency policy and programmes in the uk from 1973 to 2013. Energy Efficiency, 7(1), 23-41.

Merritt, J Q (1998) EM into SME won't go? Attitudes, awareness and practices in the London Borough of Croydon. Business Strategy and the Environment, 7(2), 90-100.

Morell, P (2015) Collaboration for change: The Edge Commission report on the future of professionalism. http://bit.ly/1Ely4Hd. Date accessed 15 Mar 2016.

Myers, D (2005) A review of construction companies' attitudes to sustainability. Construction Management and Economics, 23(8), 781-5.

Palmer, J (2000) Helping small and medium-sized enterprises improve environmental management: Lessons from proactive small and micro firms. In: Hillary, R (Ed.), Small and medium-sized enterprises and the environment: Business imperatives, pp. 325-41. Sheffield: Greenleaf Publishing. 
Petts, J (2000) Small and medium-sized enterprises and environmental compliance. In: Hillary, R (Ed.), Small and medium-sized enterprises and the environment, pp. 49-60. Sheffield: Greenleaf Publishing.

Petts, J, Herd, A and O'hEocha, M (1998) Environmental responsiveness, individuals and organizational learning: SME experience. Journal of Environmental Planning and Managment, 41(6), 711-30.

Potter, J and Hepburn, A (2005) Qualitative interviews in psychology: Problems and possibilities. Qualitative Research in Psychology, 2, 38-55.

Quinn, J (1997) Personal ethics and business ethics: The ethical attitudes of owner/managers of small business. Journal of Business Ethics, 16, 119-27.

Rajkovich, N B, Kwok, A G and Larsen, L (2013) Leed, collaborative rationality, and green building public policy. In: Henn, R L and Hoffman, A J (Eds.), Constructing green: The social structures of sustainability, pp. 57-76. London: The MIT Press.

Revell, A (2007) The ecological modernisaton of smes in the uk's construction industry. Geoforum, 38, 114-26.

Revell, A and Blackburn, R (2005) The business case for sustainability? An examination of small firms in the uk's construction and restaurant. Business Strategy and the Environment, 16, 404-20.

RIBA (2014) Business benchmarking analytical report - final, Royal Institute of British Architects.

Roxas, B and Coetzer, A (2012) Institutional environment, managerial attitudes and environmental sustainability orientation of small firms. Journal of Business Ethics, 111, 461-76.

Ryan, R M and Deci, E L (2000) Self-determination theory and facilitation of intrinsic motivation, social development and well-being. American Psychologist, 55(1), 68-78.

Sayce, S, Ellison, L and Parnell, P (2007) Understanding investment drivers for uk sustainable property. Building Research and Information, 35(6), 629-43.

Schwartz, S H (1992) Universals in the content and structure of values - theoretical advances and empirical tests in 20 countries. Advances in Experimental Social Psychology, 25, 1-65.

Schweber, $L$ (2013) The effect of breeam on clients and construction professionals. Building Research and Information, 41(2), 129-45.

Simpson, M, Taylor, N and Barker, K (2004) Environmental responsinility in smes: Does it deliver competitive advantage? Business Strategy and the Environment, 13(3), 156-71.

Smith, A, Kemp, R and Duff, C (2000) Small firms and the environment. In: Hillary, R (Ed.), Small and medium-sized enterprises and the environment, pp. 24-34. Sheffield: Greenleaf Publishing.

Smyth, H (2013) Green or maturing? Environmental sustainability in marketing and business development amongst construction majors. In: 7th Nordic Conference on Construction Economics and Organization, Klakegg, O J, Ed., Trondheim: Akademika Forlag, 1-13.

Steg, L, Dreijerink, L and Abrahamse, W (2005) Factors influencing the acceptability of energy policies: A test of vbn theory. Journal of Environmental Psychology, 25(4), 415-25.

Stern, P C (2000) Toward a coherent theory of environmentally significant behavior. Journal of Social Issues, 56(3), 407-24.

Stern, P C, Dietz, T, Abel, T, Guagnano, G A and Kalof, L (1999) A value-belief-norm theory of support for social movements: The case of environmentalism. Human Ecology Review, 6, 81-97.

Sunding, L and Ekholm, A (2015) Applying social sciences to inspire behavioural change in the construction sector: An experimental study. Construction Management and Economics, 33(9), 695-710.

Tan, Y, Shen, L and Yao, H (2011) Sustainable construction practice and contractors' competitiveness: A preliminary study. Habitat International, 35, 225-30.

Tilley, F (2000) Small firms' environmental ethics - how deep do they go? In: Hillary, R (Ed.), Small and medium-sized enterprises and the environment, pp. 35-48. Sheffield: Greenleaf Publishing.

Tzschentke, N A, Kirk, D and Lynch, P A (2008) Going green: Decisional factors in small hospitality operations. International Journal of Hospitality Management, 27, 126-33. 
United Nations Environmental Programme (2014) Greening the building supply chain. http://bit.ly/10m7hBn. Date accessed 15 Mar 2016.

Urban, J and Scasny, M (2012) Exploring domestic energy-saving: The role of environmental concern and background variables. Energy Policy, 47, 69-80.

Vallet, F, Eynard, B, Millet, D, Mahut, S G, Tyl, B and Bertoluci, G (2013) Using eco-design tools: An overview of experts' practices. Design Studies, 34(3), 345-77.

Van Hemel, C and Brezet, L (1997) Ecodesign: A promising approach to sustainable production and consumption, Paris: United Nations Environmental Programme.

Van Hemel, C and Cramer, J (2002) Barriers and stimuli for ecodesign in SMEs. Journal of Cleaner Production, 10, 439-53.

Vickers, I (1999) Clearner productio and organizational learning. Technology Analysis and Strategic Management, 11(1), 75-94.

Walley, L (2000) The environmental champion: Making a start. In: Hillary, R (Ed.), Small and mediumsized enterprises and the environment: Business imperatives. Sheffield: Greenleaf Publishing.

Whitmarsh, L (2011) Scepticism and uncertainty about climate change: Dimensions, determinants and change over time. Global Environmental Change, 21(2), 690-700.

Whitmarsh, L and O'Neill, S (2010) Green identity, green living? The role of pro-environmental selfidentity in determining consistency across diverse pro-environmental behaviours. Journal of Environmental Psychology, 30(3), 305-14.

Wiener, B (1992) Human motivation: Metaphors, theories, and research. London: Sage.

Willig, C (2001) Introducing qualitative research in psychology: Adventures in theory and method. Maidenhead, Berkshire: Open University Press.

Yardley, L (2000) Dilemmas in qualitative health research. Psychology and Health, 15, 215-28.

World Commission on Environment and Development. (1987). Our Common Future. Oxford: WCED. 